\title{
Landslide hazard mapping using limit equilibrium method with GIS application of roadway traversing mountain slopes: The case of Kitaotao Bukidnon, Philippines
}

\author{
*Ma. Catherine Q. Arca ${ }^{1,2}$ and Glen A. Lorenzo ${ }^{2}$ \\ ${ }^{I}$ Central Mindanao University, Musuan, Maramag, Bukidnon, Philippines \\ ${ }^{2}$ Graduate School of Engineering, Mindanao State University- Iligan Institute of Technology, Iligan City, Philippines \\ *Corresponding author: cathiearc1580@gmail.com
}

\begin{abstract}
The national highway section of the Municipality of Kitaotao along the Davao City route plays a vital role in the transport of goods and services in the region. However, this national highway is prone to rainfall-induced landslides. Records show that almost every year this highway is being disrupted by landslide and road clearing operations would take several hours or even up to several days. This study aimed to improve the present landslide hazard map using Limit Equilibrium Method (LEM) and GIS techniques in order to present the spatial distribution of Factor of Safety (FS) in the area. A LEM based software (SLOPE /W) was utilized in the present study and Bishop Simplified slope stability model was adopted in calculating the FS. Geotechnical properties like cohesion, friction angle and unit weight were used in the analyses. The soil thickness data gathered were correlated to the slope angle in order to determine the spatial distribution of soil thickness in the area. The LHZM revealed that areas with low to very low stability are extensively found in the southern part and some areas in the northern portion. The accuracy of the model was validated through actual field observations and also by overlying the landslide inventory over the LHZM. It was found that $77.80 \%$ of inventoried landslides are in low to very low stability zones. The present study adapts a deterministic approach using LEM of slope stability analysis and clusters the hazard zonation in terms of the spatial variation of FS in every $20 \mathrm{~m}$ x $20 \mathrm{~m}$ slope area employing GIS techniques; hence, this provides better insight on the landslide susceptibility throughout the study area and can be used directly for engineering design purposes.
\end{abstract}

Keywords: Landslide, Limit equilibrium method, Slope stability, Kitaotao, Bukidnon, Philippines

Paper Received: 31 Jan 2018

Paper Accepted: 25 March 2018

\section{INTRODUCTION}

In many developing regions slope failures constitute a continuing and serious impact on the social and economic structure, of which the true measure is not in monetary units but rather in disruption and attendant misery of human lives (Varnes, 1984). In the Philippines, landslides are dominantly associated in the areas with steep slopes, road cuts and moist soil conditions due to intense rainfall. The commonly observed slope failures in the country include block slide, debris slide and earth creep (Opiso et al., 2015).

Landslides in mountainous terrain often occur during or after heavy rainfall, resulting in the loss of life and damage to the natural and/or built environment. Mapping or delineating areas susceptible to landslides is essential for land-use activities and management decision-making in mountainous areas (Dai and Lee, 2001). The national highway section of the Municipality of Kitaotao along the Davao City route in Mindanao, Philippines traverses the mountain slopes in Bukidnon. This route plays a vital role in the transport of goods and services in the region. However, this national highway is prone to rainfall-induced landslides. Records will show that almost every year this highway is being disrupted by landslide. Depending on the extent of the damage, traffic flow disruption will take several hours or even up to several days.

Despite the mitigation projects implemented by the Department of Public Works and Highways (DPWH) and the Geohazard Mapping and Assessment Program conducted by Mines and Geosciences Bureau (MGB), these problems remain unresolved. Moreover, the present landslide susceptibility map in the study area provided by MGB utilized bigger land area in clustering landslide hazard susceptibility and the method employed in the generation of map was probabilistic and not based on the mechanics of soil sliding using Limit Equilibrium Method (LEM); hence, the result of this method cannot be used directly in landslide mitigation and engineering design works.

In order to improve the level of accuracy and usefulness of the present landslide hazard map within the study area, there is a need to conduct further study using correct analytical models and scientifically appropriate methodology. Based on the mechanics of soil and the theory of soil plasticity, accurate landslide susceptibility can be measured quantitatively with high degree of accuracy using physical models and LEM. These 
entail measuring the geotechnical properties of soil in addition to the determination of the actual slope geometry of the area. The present study adapts a deterministic approach using LEM of slope stability analysis and clusters the hazard zonation in terms of the spatial variation of FS in every $20 \mathrm{~m}$ x $20 \mathrm{~m}$ slope area employing GIS techniques.

\section{DESCRIPTION OF STUDY AREA}

The study was conducted along the forthy five kilometers national highway section of the Municipality of Kitaotao to Davao City route, which is situated in the southern part of Bukidnon and traverses the mountain slopes in the province. Fig. 1 shows the location of the area and the recorded landslides. A total of 35 landslide occurrences were accounted based on the site survey and data gathered from DPWH. The recorded landslides were recent and old events and the corresponding length in meters that affected the national highway is reflected in the map. In the recent inventory conducted in October 2016, a total of 12 landslide occurrences were observed, two (2) of which disrupted the traffic flow of the national highway and made it not passable due to mountainside landslide, and three (3) recorded are collapsed portion of national highway which made the national highway one lane passable.

The geology of the study area was classified into three groups based on the geologic map from Mines and Geoscience Bureau as shown in Fig. 2. Moreover, the lithologies of the area are: Geology 1 (G1): Mudstone and Limestone, Geology 2 (G2): Mudstone and Siltstone and Geology 3 (G3): Basaltic Andesite.

\section{SLOPE STABILITY MODEL USING GEOSLOPE (SLOPE /W)}

Limit equilibrium methods are still currently most used for slopes stability studies. These methods consist in cutting the slope into fine slices so that their base can be comparable with a straight line then to write the equilibrium equations: equilibrium of the forces and/or moments. The traditional methods of slices used are those of Fellenius and Bishop (Baba et al., 2012).

Using limit equilibrium, SLOPE/W can model heterogeneous soil types, complex stratigraphic and slip surface geometry, and variable pore-water pressure conditions using a large selection of soil models (Karhn, 2004). Program GeoStudio (SLOPE/W) is formulated in terms of moment and force equilibrium factor of safety equations. Analysis provides a factor of safety, defined as a ratio of available shear resistance (capacity) to that required for equilibrium (Ellen et al., 2008). The limit equilibrium procedure for calculating the factor of safety involves

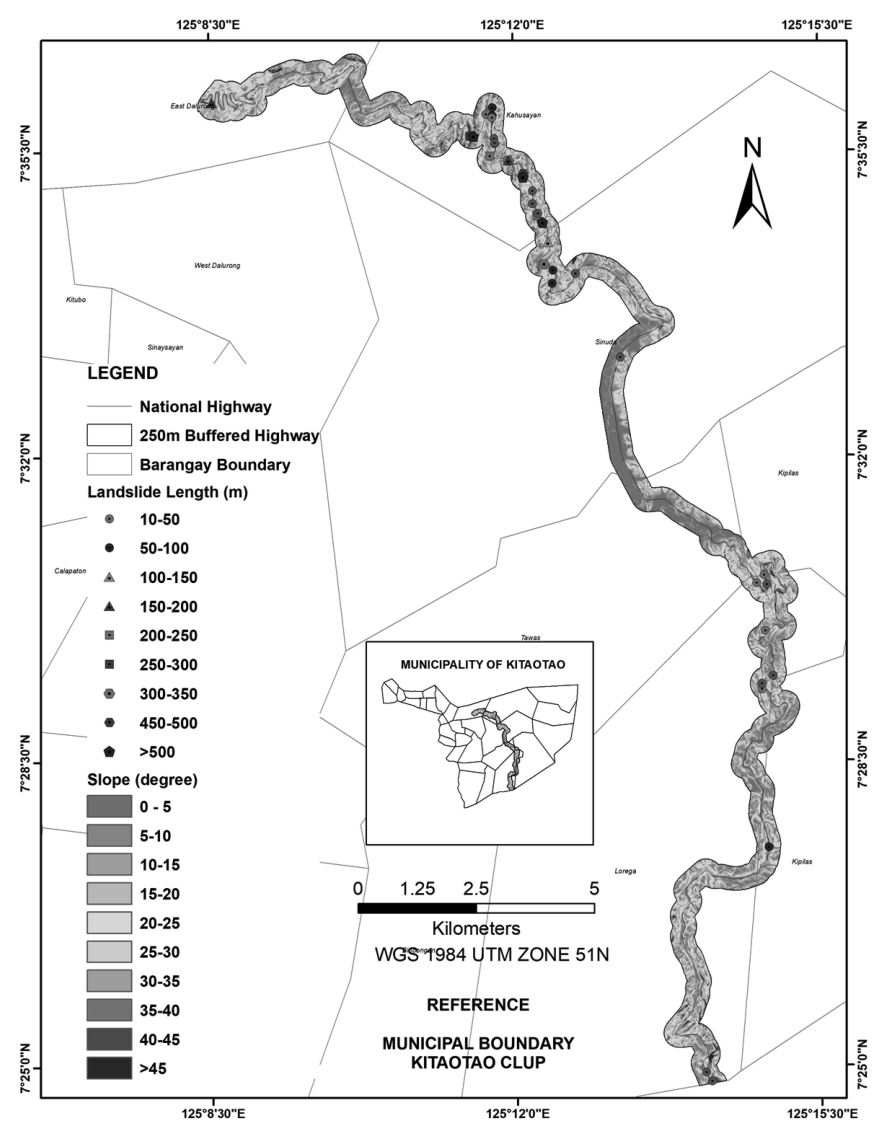

Fig. 1: Landslide inventory map

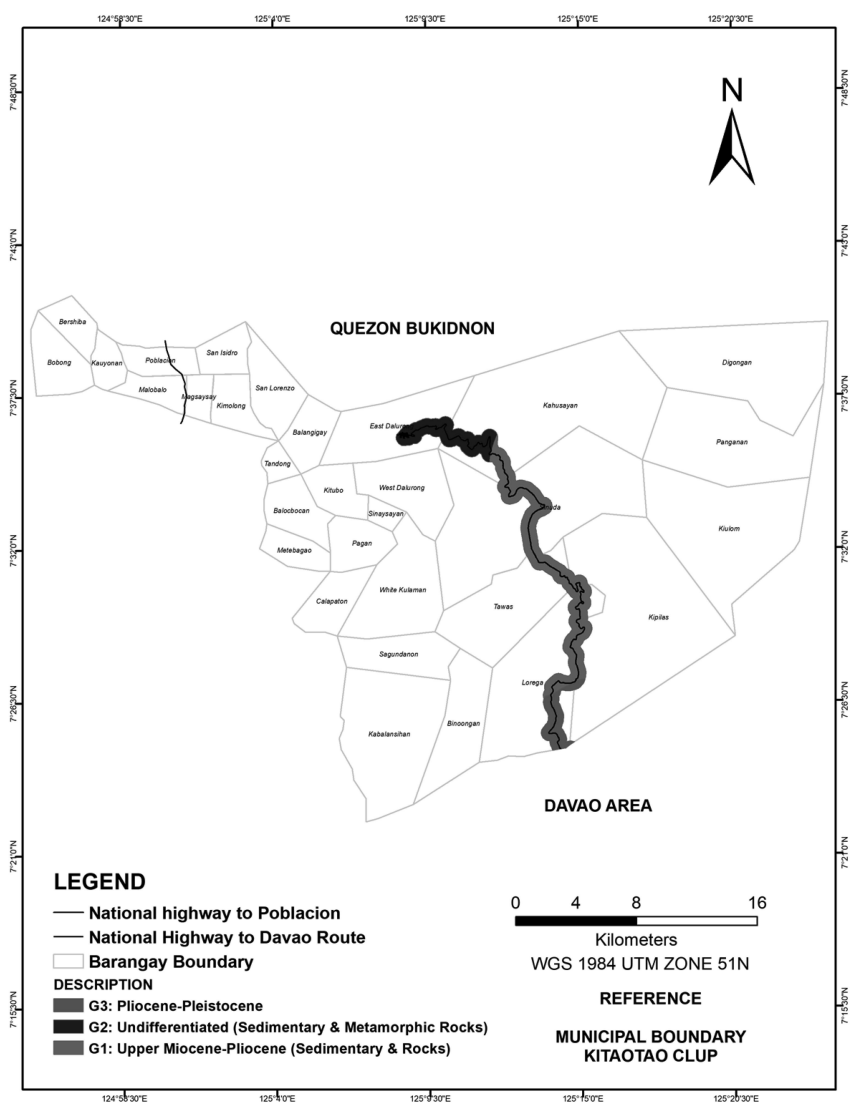

Fig. 2: Geological map of the area 
comparing the available shear strength along the sliding surface with the force required to maintain the slope in equilibrium (Karhn, 2004).

In the 1950's Professor Bishop at Imperial College in London devised a method, which considers the interslice normal forces, but ignored the interslice shear forces. Bishop developed an equation for the normal at the slice base by summing slice forces in the vertical direction. The consequence of this is that the base normal becomes a function of the factor of safety. This in turn makes the factor of safety equation nonlinear (that is, FS appears on both sides of the equation) and an iterative procedure is consequently required to compute the factor of safety (GEO-SLOPE International Ltd, 2012). An initial FS value of 1.0 is used, and a new FS is calculated. If the difference between the calculated and the assumed FS is $>0.001$, the calculated FS is used as a second FS estimate for a new FS. This process is repeated until the difference between consecutive iterations is $<0.001$. Approximately seven iterations are required for most slope and slide plane geometries (Wyllie et al., 2004). Bishop's Simplified Method (BSM) may only be used when evaluating circular slip surfaces. BSM does not satisfy all conditions of equilibrium. However, Wright et al., (1973) have shown that the FS calculated by Bishop's method agrees favorably (within $\sim 5 \%$ ) with the factor of safety calculated using finite element procedures.

$$
\mathrm{FS}=\frac{1}{\sum \mathrm{W} \sin \alpha} \sum\left[\frac{\mathrm{c} \beta+\mathrm{W} \tan \phi-\frac{c \beta}{F S} \sin \alpha \tan \phi}{m_{\alpha}}\right]
$$

where:

$$
\begin{aligned}
\mathrm{m}_{\alpha} & =\cos \alpha\left(1+\frac{\tan \phi \sin \alpha}{\mathrm{FS}}\right) \\
c & =\text { cohesion } \\
\mathrm{W} & =\text { weight of the slice } \\
\phi & =\text { angle of friction of soil } \\
\alpha & =\text { inclination of slip surface at the middle of slice. }
\end{aligned}
$$

\section{METHODOLOGY}

\section{Field sampling}

Soil samples from 18 sites were collected and sent to the laboratory for testing. A total of 60 probe holes were drilled using bucket augers to determine the soil thickness above the potential sliding/failure plane.

\section{Acquisition of slope stability parameters}

The necessary input parameters are unit weight of soil $(\gamma)$, cohesion $(c)$, angle of friction $(\phi)$, and slope angle $(\alpha)$. The

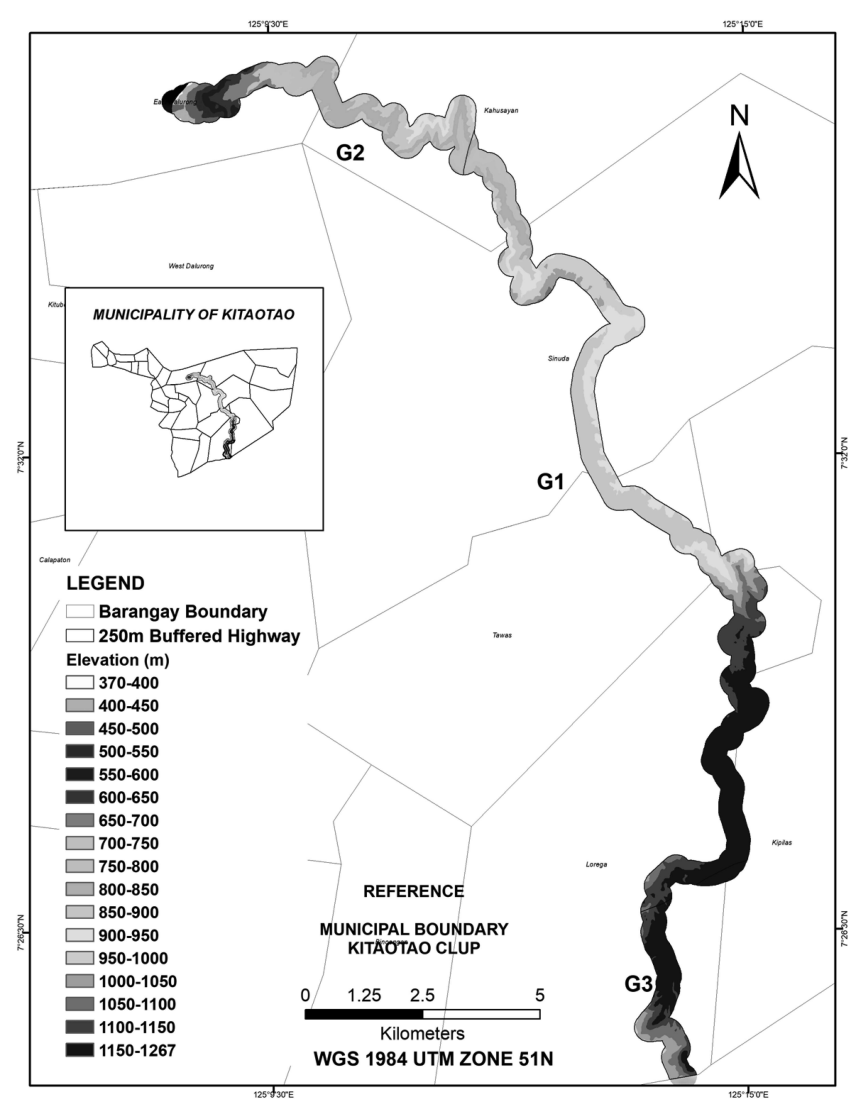

Fig. 3: Elevation map of the study area

slope and elevation of the site (Figs. 1 and 3) were extracted from a $5 \mathrm{~m}$ x $5 \mathrm{~m}$ Digital Elevation Model (DEM) using ArcGIS spatial analyst tool. The soil thickness data gathered were correlated to the slope angle in order to determine the spatial distribution of soil thickness in the study area. Direct shear test was performed iso as to determine the shear strength of the soil. The effective normal stress and the corresponding horizontal shear stress at failure for each sample are plotted to determine the Mohr-Coulomb failure envelope (Fig. 4). The minimum and average parameter values used in the analyses are shown in Table 1.

\section{Slope stability analysis procedure}

The analysis considers semi-saturated and fully saturated conditions. For semi-saturated, the shear parameters were obtained from direct shear tests. For fully saturated condition the friction angle was reduced to account for the increase in water content. This assumption was based on the inverse relationship between friction angle $(\phi)$ and moisture content (ù) observed as shown in Fig. 5. Logarithmic relationship gives $0.60 \mathrm{R}^{2}$ value, which means that with increasing moisture content, the friction angle tends to decrease. This finding agrees with the study of Wang et al. (2014). Furthermore, Dafalla (2012) studied the effects of clay and moisture content in the shear strength parameters and found that moisture content causes a drop in both cohesion and angle of internal friction. 


\begin{tabular}{|c|c|c|c|c|c|c|c|c|}
\hline \multirow{4}{*}{ Geology } & \multicolumn{8}{|c|}{ Mohr-Coulomb Parameters } \\
\hline & \multicolumn{4}{|c|}{ Average values } & \multicolumn{4}{|c|}{ Minimum values } \\
\hline & \multicolumn{4}{|c|}{ Semi-saturated Fully-saturated } & \multicolumn{4}{|c|}{ Semi-saturated Fully-saturated } \\
\hline & c (kPa) & $\phi$ (degree) & $\phi$ (degree) & $\gamma_{\mathbf{t}}\left(\mathbf{k N} / \mathbf{m}^{3}\right)$ & $\mathrm{c}(\mathbf{k P a})$ & $\phi$ (degree) & $\phi$ (degree) & $\gamma_{\mathbf{t}}\left(\mathbf{k N} / \mathbf{m}^{3}\right)$ \\
\hline G1. Upper Miocene-Pliocene & 20.6 & 17.7 & 2.6 & 14.93 & 12.4 & 20.0 & 2.6 & 16.13 \\
\hline G1. Undifferentiated & 25.2 & 21.4 & 2.6 & 15.73 & 15.8 & 23.5 & 2.6 & 16.30 \\
\hline G1. Pliocene-Pleistocene & 17.6 & 12.4 & 2.6 & 15.24 & 11.7 & 16.0 & 2.6 & 16.83 \\
\hline
\end{tabular}

There were one hundred thirty six (136) geometrical models made for the entire study area. Geometrical parameters were used to draw the configuration for each slope interval in GeoSlope (SlopelW) 2016. Stability analysis was performed using the Bishop Simplified Method (BSM). Soil unit weight, cohesion and friction angle were used as an input in the software and an entry and exit slip surface was specified to generate a failure surface.

\section{Generation of landslide hazard zonation map}

FS values of the slope intervals were transferred to their respective slope locations within the GIS framework. ArcGIS spatial analyst tool was used to generate FS maps. The values of factor of safety were group into different stability classes to develop the landslide hazard zonation map.

\section{RESULTS AND DISCUSSIONS}

\section{Slope angle and soil thickness correlation}

Exponential relationships give the highest value of $\mathrm{R}^{2}$ for the three geologic areas $(0.82$ for G1, 0.96 for G2 and 0.84 for G3) as shown in the Table 2. These findings show agreement with the trend lines presented by De Rose (2009) and Salciarini et al. (2007), describing relationship between the soil thickness

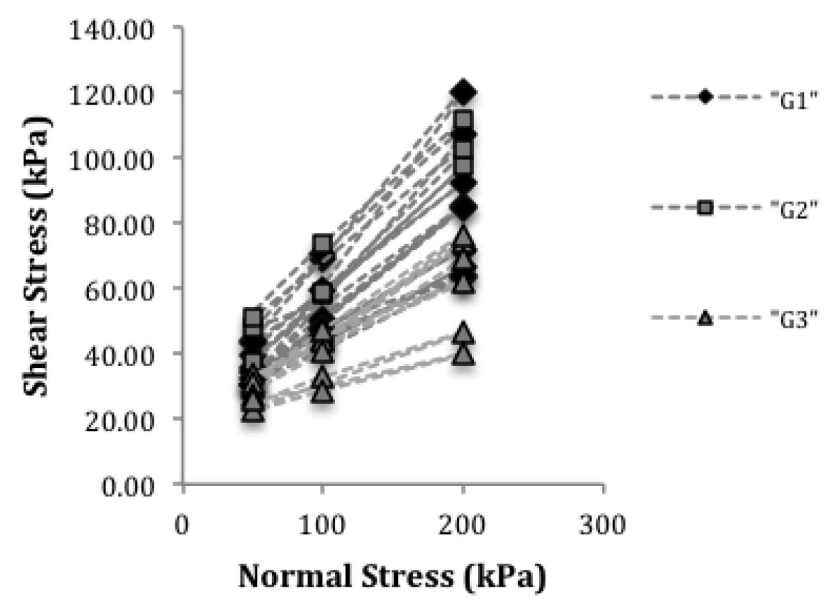

Fig. 4: Failure envelope of the soil samples and slope angle with negative exponential functions. Using the best-fit exponential equation obtained in the correlation, soil thickness of the site per slope interval was generated.

\section{Factor of safety map}

There were 2 sets of FS maps generated as shown in Figs. 6 and 7. These maps show the spatial distribution of FS in the area under two ground water conditions, which are semisaturated and fully saturated. Ground water plays a vital role in the occurrence of slope failures since water decreases the stability by increasing the pore water pressure on the potential failure surface (Bhattarai et al., 2014). When the effect of ground water is increased from semi-saturated to fully saturated condition, most of the areas experienced a decrease in FS. Areas extensively found in the southern part and some portions in the northern part have FS $<1.0$, especially under fully saturated condition. It can be observed that areas in the far northern portions have $\mathrm{FS}>1.5$ yet numerous landslides were documented. This could be attributed to previous ground movement, which may have led to the stability of slope configurations.

\section{Landslide hazard zonation map}

The values of factor of safety were grouped into six different classes to show their stability and spatial distribution.

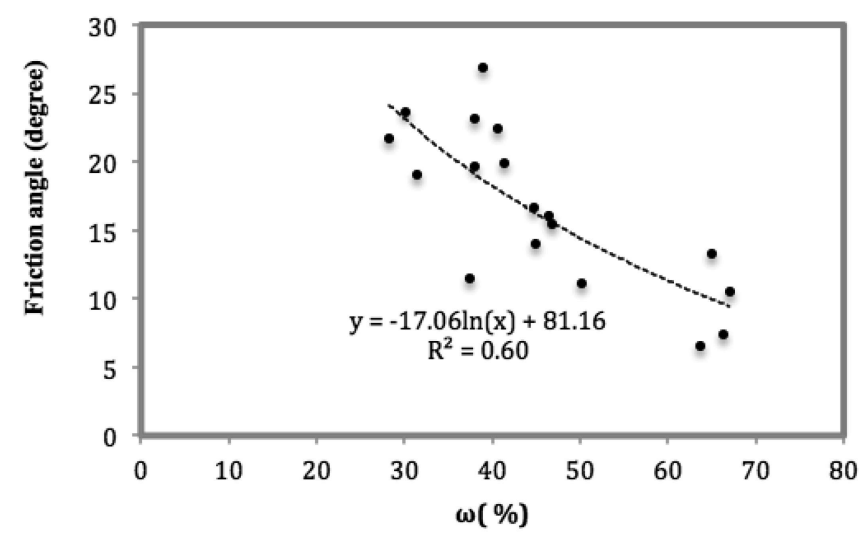

Fig. 5: Logarithmic $\omega$-f curve 
Table 2: Exponential relationship between soil thickness and slope angle of soil samples

\begin{tabular}{lll}
\hline Geology & Exponential equation & $\mathbf{R}^{\mathbf{2}}$ \\
\hline G1 & $\mathrm{y}=5.82 \mathrm{e}^{-0.04 \mathrm{x}}$ & 0.82 \\
$\mathrm{G} 1$ & $\mathrm{y}=4.16 \mathrm{e}^{0.05 \mathrm{x}}$ & 0.96 \\
$\mathrm{G} 1$ & $\mathrm{y}=-6.016 \mathrm{e}^{-0.05 \mathrm{x}}$ & 0.84 \\
\hline
\end{tabular}

Table 3 presents the ranking of the areas according to landslide stability. Although a value of $F S=1.0$ is considered to be the critical value in evaluating the stability of slope, it can be seen in Table 3 that FS range 1.0-1.25 is described having moderate landslide hazard. This is due to the variability of strength parameters and the inconsideration of heterogeneous soil masses, thus over estimation of these parameters could be possible.

The landslide hazard zonation map of Kitaotao, Bukidnon is presented in Fig. 8. Based on the results, steeper slopes, high cohesion values and the effect of ground water are the major contributing factors for landslides susceptibility. From the given stability classes, the generated hazard zonation map revealed that most of the areas in southern part and some portions in the northern side have low to very low stability. Moreover, when the effect of ground water is increased from semi-saturated to fully saturated condition, most of the areas experienced a decrease in FS. Apparently, ground water plays a vital role in

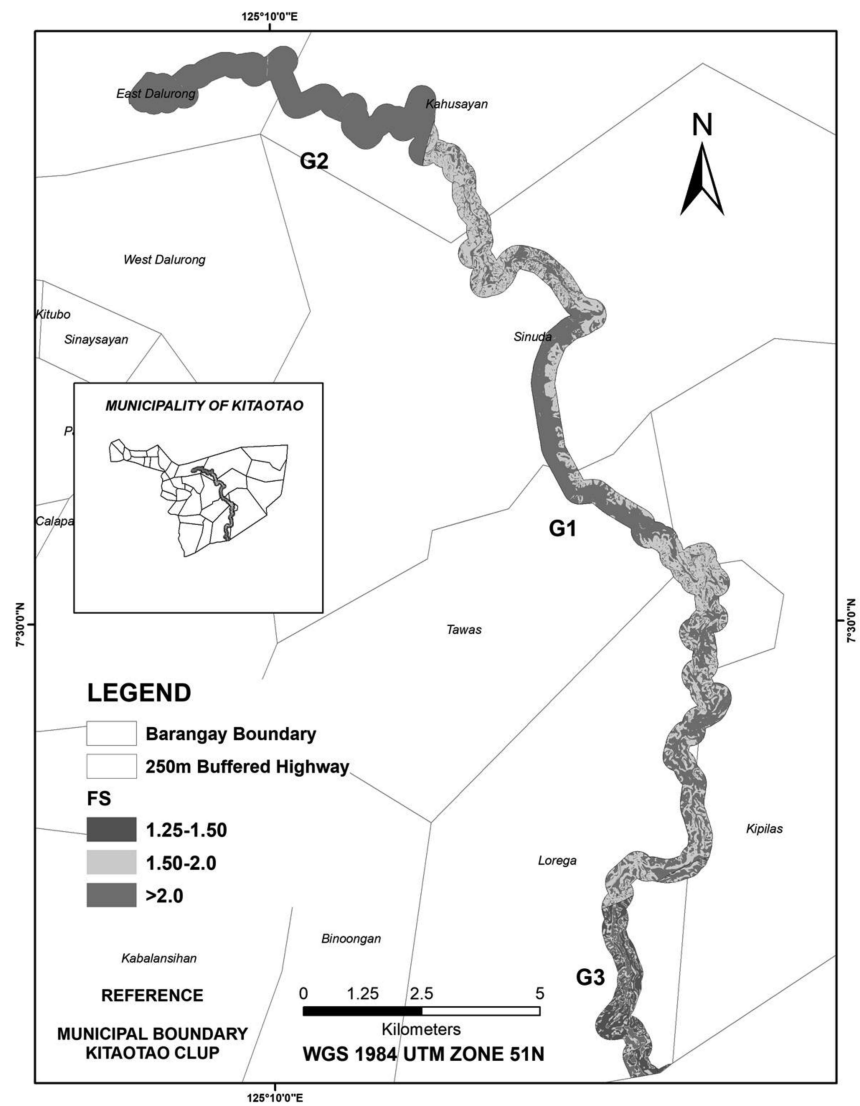

Fig. 6: FS Map semi-saturated condition
Table 3: Degree of stability

\begin{tabular}{lll}
\hline FS & Stability class & Description \\
\hline $0-0.50$ & Unstable & Landslides are expected to occur \\
$0.50-1.0$ & Very Low & Landslides are likely to occur \\
$1.0-1.25$ & Low & Moderate landslide hazard exists \\
$1.25-1.50$ & Moderate & Minor landslide hazard exists \\
$1.50-2.0$ & High & Landslides are not likely to occur \\
$>2$ & Very High & Safe slopes \\
\hline
\end{tabular}

the occurrence of slope failures since water decreases the stability by increasing the pore water pressure on the potential failure surface (Bhattarai et al., 2014).

\section{Validation of model}

The accuracy of the model was validated through actual field observations and also by overlying the landslide inventory over the LHZM. It was found that $77.8 \%$ of inventoried landslides fell in low to very low stability zones and $22.2 \%$ of the inventoried landslides located at the far northern part were in high to very high stability zones. According to Rabonza et al. (2014), there may be some cases that those old landslides, when their location became more stable after the landslide event, will appear to be stable when the recent DEMs are used.

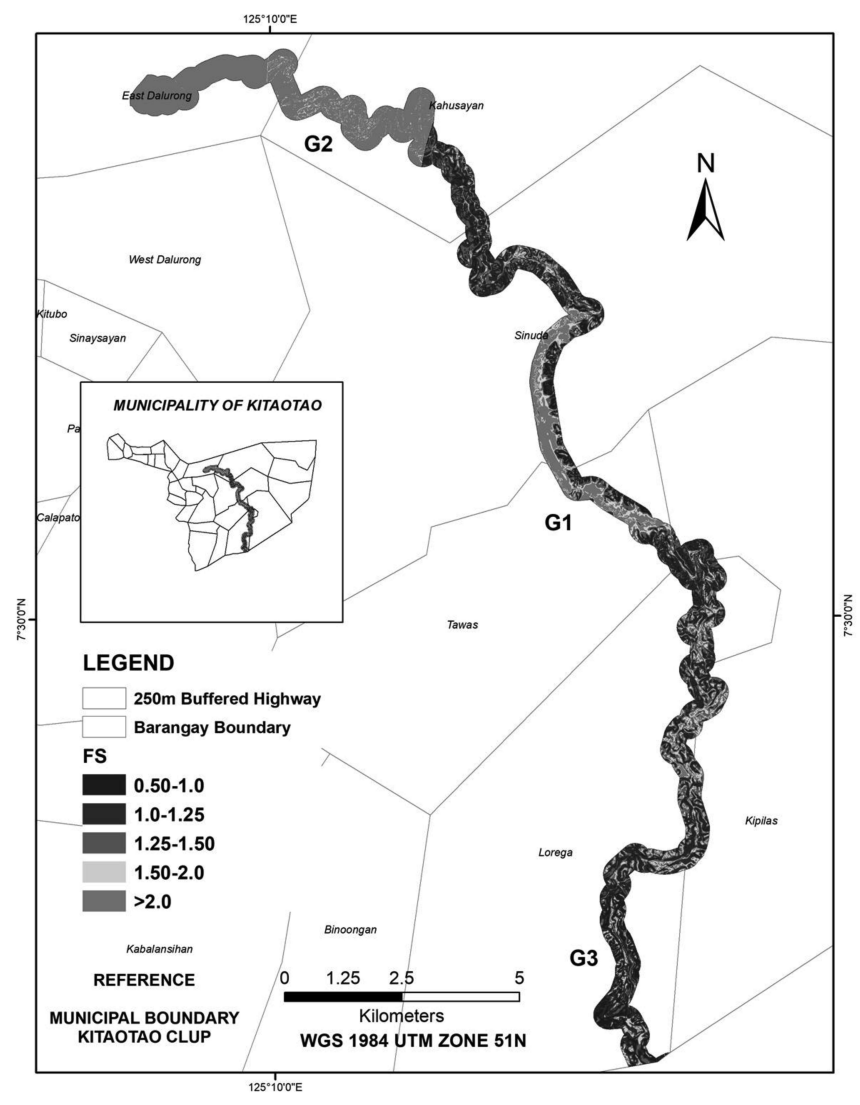

Fig. 7: FS Map fully-saturated condition 


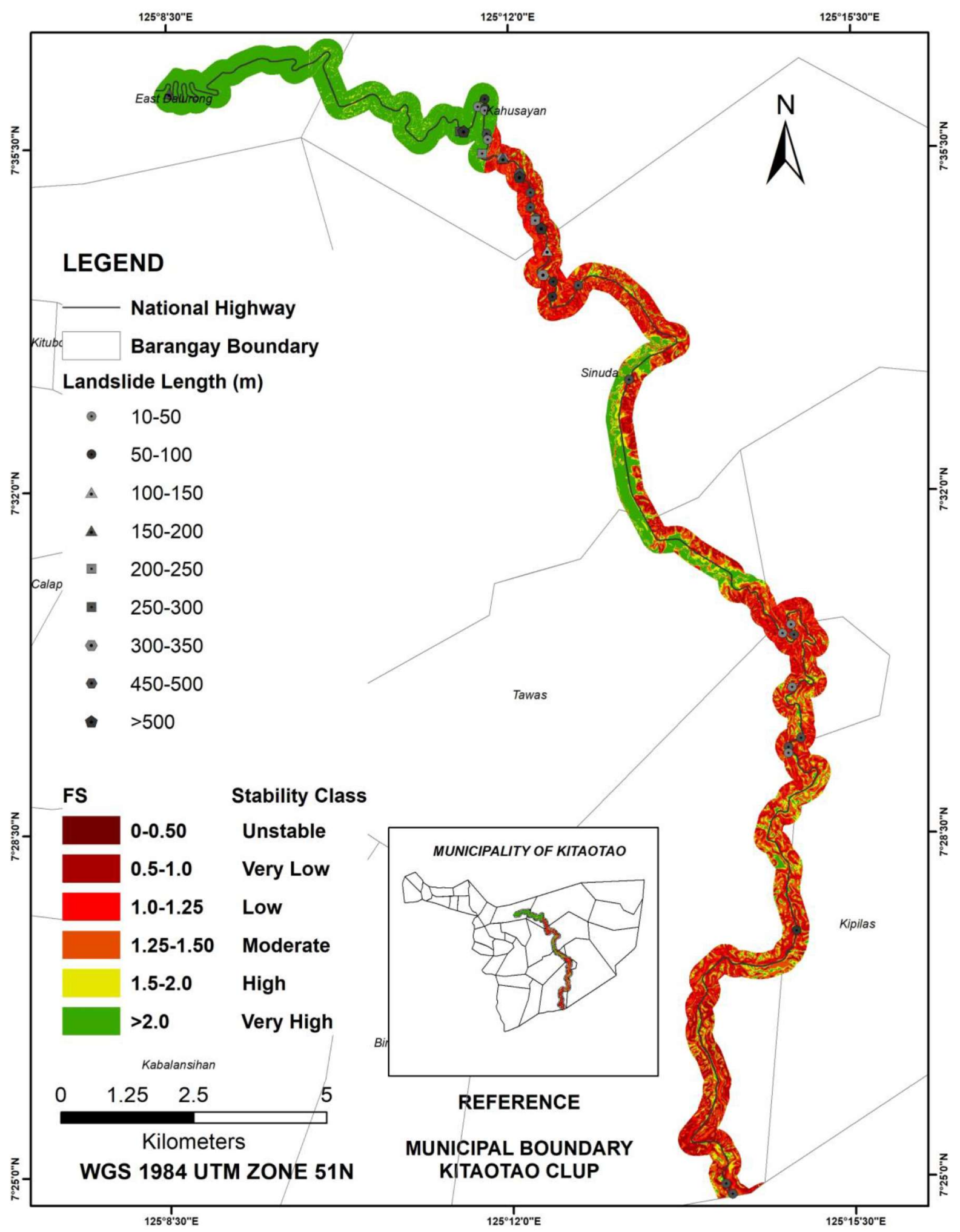

Fig. 8: Landslide hazard zonation map of Kitaotao, Bukidnon 
Two Landslide Susceptibility Index (LSI) maps are available in the area. One of these is generated by MGB (Fig. 9), which is mainly based on slope and utilized bigger land area in clustering landslide hazard susceptibility. Another LSI map (Fig. 10) generated from the study of Opiso et al. (2015), which used the frequency ratio approach. The method employed in the generation of both maps was probabilistic and not based on the mechanics of soil sliding using LEM; hence, these maps cannot be used directly in landslide mitigation and engineering design works. The present study adapts a deterministic approach using LEM of slope stability analysis and clusters the hazard zonation in terms of the spatial variation of FS in every $20 \mathrm{~m}$ x $20 \mathrm{~m}$ slope area employing GIS techniques.

\section{CONCLUSIONS}

This study was endeavored in order to improve the accuracy and usefulness of the available landslide susceptibility index map in the study area. This present study generated a new, improved and localized landslide hazard zonation mapping reflecting the factor of safety using the Limit Equilibrium Method (LEM) and employing GIS techniques in order present the spatial distribution of FS of the national highway section of the Municipality of Kitaotao along the Davao City route.
The FS results showed good agreement with the actual landslides that occurred. Furthermore, the landslide hazard zonation map developed during this research will allow future researchers and investigators to utilize data that this study has accumulated. The workflow developed in this study can be readily adapted to similar research at other localities. Finally, the landslide hazard zonation map developed in this research displays the Factor of Safety. These FS values are obtained deterministically and hence, provide better insight on the landslide susceptibility throughout the study area and can be used directly for engineering design purposes.

\section{ACKNOWLEDGMENT}

The authors gratefully acknowledge the financial support of Department of Science and Technology - Engineering Research and Development for Technology (DOST-ERDT).

\section{REFERENCES}

Baba, K., Bahi, L., Ouadif, L., and Akhssas, A., 2012, Slope stability evaluations by limit equilibrium and finite element methods applied to a railway in the Moroccan Rif. Scientific Research, Open Journal of Civil Engineering, v. 2, pp. 27-32.

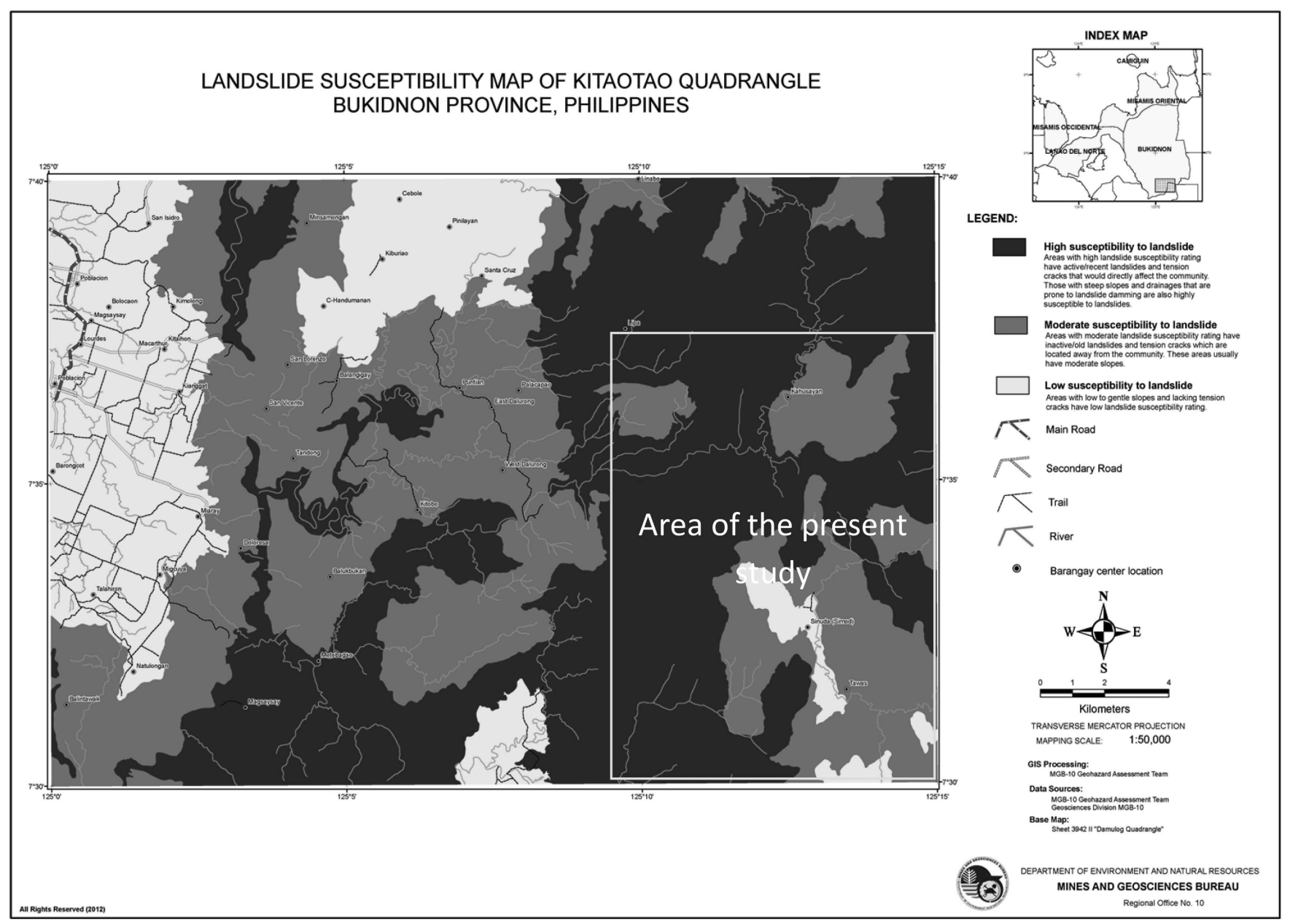

Fig. 9: Landslide susceptibility map of Kitaotao, Bukidnon by MGB 


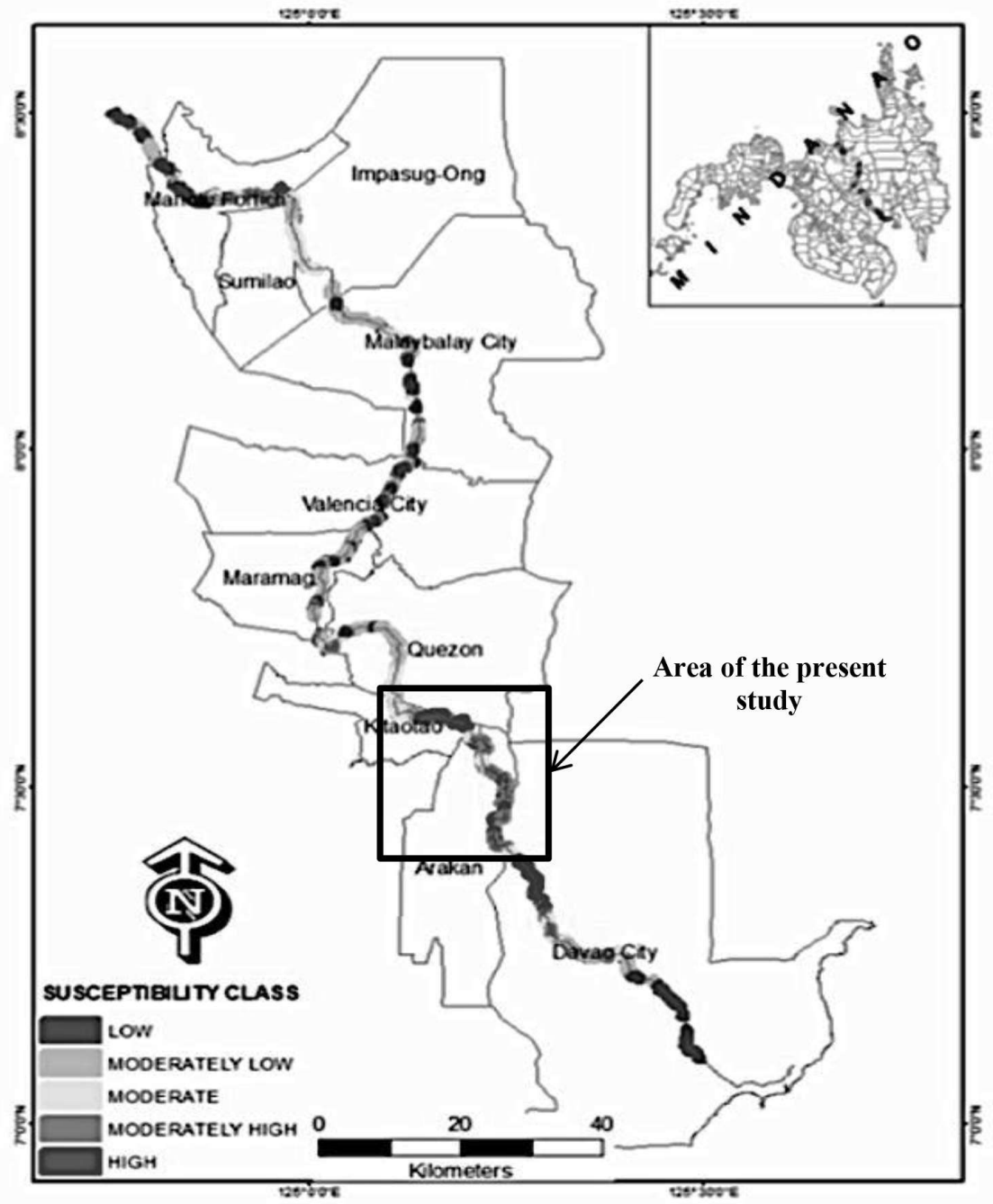

Fig. 10: Landslide Susceptibility Index Map (Opiso et al., 2015)

http://dx.doi.org/10.4236/ojce.2012.21005

Bhattarai, P., Tiwari, B., Marui, H., and Aoyama, K., 2014, Quantitative slope stability mapping with ArcGIS: Prioritize high-way maintenance. Research Gate, Available at https://www.researchgate.net/publication/265119127.

Dafalla, M. A., 2012, Effects of clay and moisture content on direct shear tests for clay-sand mixtures, Hindawi Publishing Corporation, v. 2013, pp. 1-8.

Dai, F.C. and Lee, C.F., 2001, Landslide characteristics and slope instability modeling using GIS, Lantau Island, Hong Kong. Elsevier, v. 42, pp. 213-228.

De Rose, R. C., 2009, Quantifying sediment production in steepland environments. Eurasian Journal of Forest Research. v. 12(1). pp 9-46.

Ellen, E., Haugen, D., and Kaynia, A.M., 2008, A comparative study of empirical models for landslide prediction using historical case histories, The 14th World Conference on Earthquake Engineering, October12-17, Norwegian Geotechnical Institute, Beijing, China, pp. 1-8.

Karhn, J., 2004, Stability Modeling with Slope/W: An Engineering Methodology, first edition, $17 \mathrm{p}$.

Opiso, E. M., Puno G. R., Detalla A. L., and Alburo J. L. P., 2015, Rainfall-induced landslide susceptibility zonation along the Cagayan de Oro City (CDO) - Bukidnon -Davao City route corridor. KCE, Journal of Civil Engineering, v. 20(6), pp. 2506-2512. https://doi.org/10.1007/s1220

Rabonza, M.L., Felix, R.P., Ortiz, I.J.G., Alejandrino, I.K.A, Aquino, D.T., Eco, R.C., Lagmay, A.M.F.A., 2014, Shallow landslide susceptibility mapping for selected areas in the Philippines severely affected by super typhoon Haiyan. NOAH Open File Reports. v. 3, pp. 28-36.

Salciarini, D., Godt, J.W., Savage, W. Z., Baum, R.L., and Conversini, P., 2007, "Modelling the rainfall-induced 
developments of shallow landslide in eastern Umbria, central Italy, using the TRIGRS (Transient Rainfall Infiltration and Grid-based Slope-Stability approach" Presented at the 1st North American Landslide Conference, At Vail, Colorado (USA), ResearchGate, pp. 294-304.

Stability Modelling with SLOPE/W, GEO-SLOPE International Ltd., 2012, Canada.

Varnes, D.J., 1984, Landslide hazard zonation: A review of principles and practice. United Nations Educational, Scientific and Cultural Organization (UNESCO), France, pp. 9-63.
Wang, L., Long, W., and Gao, S., 2014, Effect of moisture content, void ratio and compacted sand content on the shear strength of remolded unsaturated clay. Electronic Journal of Geotechnical Engineering, v. 19, pp. 4413-4426.

Wright, S.G., Kulhawy, F.H., and Duncan, J.M., 1973, “Accuracy of equilibrium slope stability analysis," Journal of the Soil Mechanics and Foundations Division, American Society of Civil Engineers, v. 99(10), pp. 783-791.

Wyllie, D.C. and Mah, C.W., 2004, Rock slope engineering, 4th Edition, Spoon Press, pp. 188-192. 
